\title{
How to coordinate the relationship
} between renewable energy consumption and green economic development: from the perspective of technological advancement

\author{
Fangming Xie ${ }^{1}$, Yali Liu ${ }^{1 *} \mathbb{D}$, Fangyuan Guan ${ }^{1}$ and Ning Wang ${ }^{2}$
}

\begin{abstract}
Background: Green economic development refers to reducing pollution emissions and increasing production efficiency while promoting economic growth. Although the renewable energy consumption is "green," it may not promote green economic development due to the constraints of existing technical conditions. Therefore, the technological advancement approach that can help coordinate the relationship between renewable energy consumption and green economic development should be identified. That is, determining whether to develop new technologies or improve existing technologies should be paid more attention in the context of continuous increase in renewable energy consumption.
\end{abstract}

Results: (1) The inverted N-shaped relationship between renewable energy consumption and green economic development under the existing technical conditions. The degree of renewable energy consumption can merely promote green economic development in the interval of $0.67-10.87$. That is, the renewable energy consumption (\% of total energy consumption) is less than $0.67 \%$ or greater than $10.87 \%$, which is not conducive to green economic development. (2) Developing new technologies can stimulate the positive effect of renewable energy consumption on green economic development. However, the improvement of existing technologies fails to exhibit an effective impact on the relationship between renewable energy consumption and green economic development. (3) Coordinating the relationship between renewable energy consumption and green economic development can also be achieved by reducing the dependence of Gross Domestic Product (GDP) on fossil fuels. (4) The stage of economic development might impact the effect of renewable energy on green economic development.

Conclusions: It is particularly important to improve technological innovation capabilities, especially in countries with a high proportion of renewable energy consumption. In addition, the government should guide the funds and resources to the renewable energy industry through the credit rationing system to promote the transition of the industrial structure to an environmentally friendly direction. For countries with relatively low levels of economic development, this does not mean that these countries should reduce their demand for renewable energy. Instead, these countries need to take more proactive measures, such as increasing technological innovation capabilities and

\footnotetext{
*Correspondence: m15951758966@163.com

${ }^{1}$ School of Management, China University of Mining \& Technology,

Xuzhou 221116, China

Full list of author information is available at the end of the article
} in this article are included in the article's Creative Commons licence, unless indicated otherwise in a credit line to the material. If material is not included in the article's Creative Commons licence and your intended use is not permitted by statutory regulation or exceeds the permitted use, you will need to obtain permission directly from the copyright holder. To view a copy of this licence, visit http://creativeco mmons.org/licenses/by/4.0/. 
optimizing industrial structure to coordinate the relationship between renewable energy consumption and green economic development.

Keywords: Renewable energy consumption, Green economic development, Global Malmquist-Luenberger, Technological innovation, Technological improvement

\section{Background}

Although energy consumption is still dominated by fossil energy consumption in recent years, the rapid growth of renewable energy consumption indicates that the development and use of renewable energy will gradually replace fossil energy. Countries worldwide are actively developing and using renewable energy to achieve the United Nations Sustainable Development Goals [1] and to prepare for sustainable development. The European Union (EU) holds the world's leading renewable energy technologies and a high demand for renewable energy. Therefore, the development and use of renewable energy in EU have recently achieved certain results. Figure 1 illustrates that the proportion of renewable energy consumption has grown rapidly in EU from 2008 to 2018.

To achieve sustainable development, the European Parliament proposed in 2017 that the EU's renewable energy consumption should account for 35\% of total energy consumption by 2030 [3]. The pace of renewable energy consumption is predicted to accelerate, and the intensity of renewable energy consumption will exceed and consequently replace fossil energy. The BP Statistical Review of World Energy classifies renewable energy sources as wind, geothermal, solar, biomass and waste, among others. As an environmentally friendly resource, renewable energy is certainly "green," but it fails to necessarily promote "development." For instance, fossil energy uses considerably more time and a wider range than renewable energy, and is more suitable for current production technology. That is, the role of renewable energy consumption in green economic development is subject to existing technical conditions. Therefore, an investigation of whether technological advances help coordinate the relationship between renewable energy consumption and green economic development must be undertaken. In addition, we should determine whether new technologies must be developed or existing ones must be improved. In the context of the rapidly growing renewable energy consumption, countries struggle to stimulate the renewable energy consumption to acquire a positive effect on green economic development.

The Organization for Economic Co-operation and Development (OECD) defines green economic development as the promotion of economic growth while ensuring that the nature can continuously provide resources and environmental services for humans' wellbeing [4].

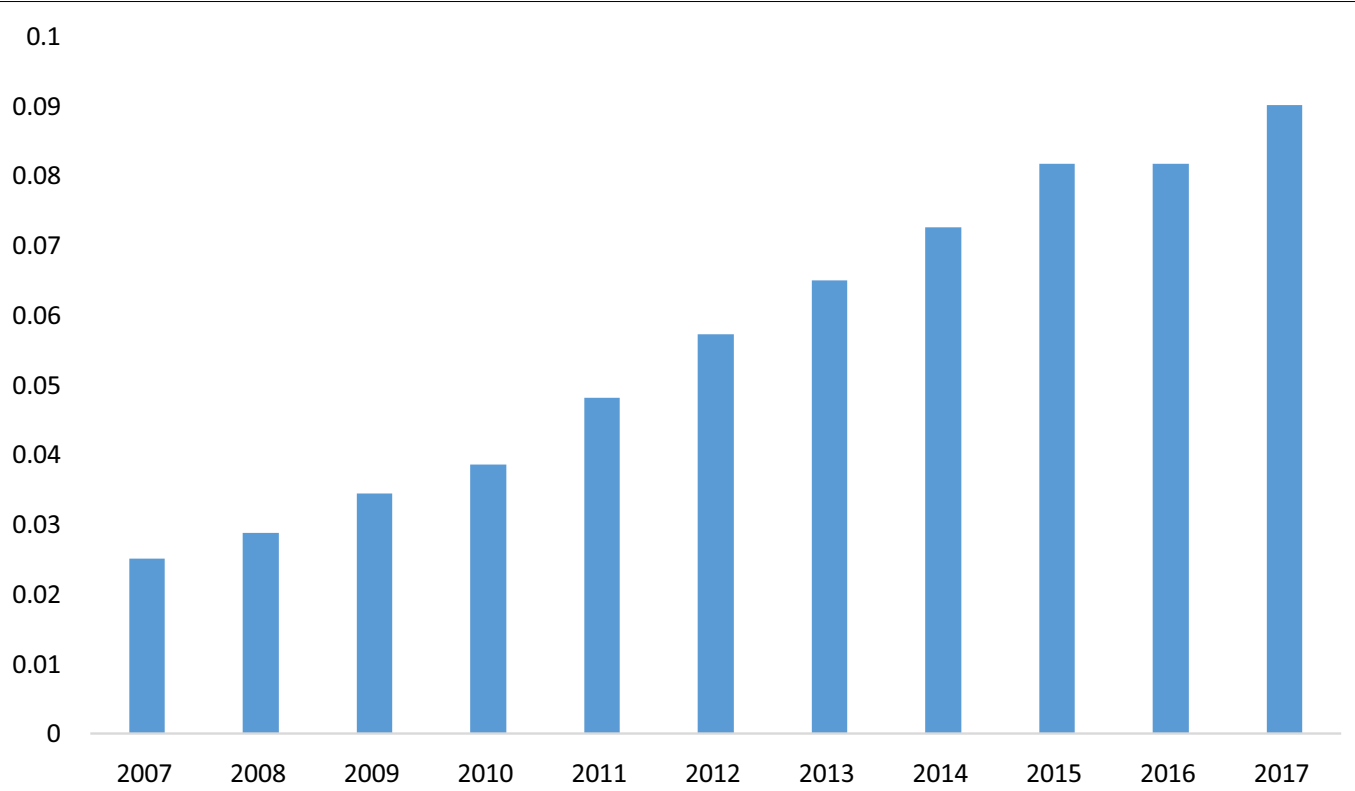

Fig. 1 Renewable energy consumption (\% of total energy consumption) in EU. Data Sources: BP Statistical Review of World Energy, 2019 [2] 
However, in some cases, it is difficult to achieve a winwin situation for economic growth and environmental protection due to the intertemporal effects. We believe the intertemporal effect in terms of both economic development and renewable energy consumption. Therefore, due to the existence of intertemporal effects, we need to consider the impact of renewable energy consumption on green economic development at different stages of renewable energy development and different stages of economic development. Green economic development should be the focus of research, whether during the economic depression or the early stage of renewable energy development, even when the use of renewable energy generates a lot of costs and has a negative impact on the economy. The OECD believes that we must look to the future and find new ways to ensure growth and development. It is not wise to return to the traditional development mode. The final result of the extensive economic growth model may increase production costs, curb economic development, and cause irreversible problems such as excessive use of resources, pollution, climate change and loss of biodiversity. Therefore, this study believes that the only way to ensure sustainable development is to promote economic growth while improving production efficiency and reducing emissions. By investigating the relationship between renewable energy consumption and green economic development, this study can provide scientific policy recommendations for immediately achieving sustainable development.

This paper is unique given that it employs the global Malmquist-Luenberger index based on slacks-based measure (SBM-GML) approach to measure the green economic development among the 27 EU Member States. This paper aims to analyze whether developing new technologies or improving existing technologies can coordinate the relationship between renewable energy consumption and green economic development. Moreover, this study integrates the empirical results to outline scientific policy recommendations.

The remainder of this study is organized as follows. "Literature review" section reviews related studies; "Theoretical analysis and assumptions" section describes the data and the methodology; "Methodology" section combines the empirical results to propose four conclusions, and "Results and discussion" summarizes the main findings and proposes scientific policy recommendations.

\section{Literature review}

Relevant studies mainly discuss the relationship between renewable energy consumption and economic growth, but consistent conclusions have not been reached.

First, certain studies have indicated that the renewable energy consumption will acquire a positive impact on economic growth. This finding was supported by the fact that renewable energy consumption can completely replace fossil energy consumption and promote economic growth along with fossil energy.

Tugcu et al. indicated that renewable and fossil energy consumption can likewise acquire a positive impact on economic growth in G7 countries [5]. Lin and Moubarak proved that China's economic growth benefits from the renewable energy industry. That is, renewable energy consumption can support China's economic growth [6]. Apergis and Payne [7], Sebri and Ben-Salha [8], and Marinas et al. [9] proved the long-term bidirectional Granger causality between renewable energy consumption and economic growth and found that the renewable energy consumption can enhance economic growth. Shafiei and Salim [10], Bhattachary et al. [11], Paramati et al. [12], and Rahman and Velayutham [13] asserted that the renewable energy consumption acquires a positive effect on economic activities. Lnglesi-Lotz pointed out that increasing the intensity of renewable energy consumption solves environmental pollution and improves the level of economic growth [14]. Alper and Oguz used the Auto Regressive Distributed Lag (ARDL) approach to prove that renewable energy consumption acquires positive effects on economic growth for all EU member states [15]. Eren et al. used the Dynamic Ordinary Least Squares approach and proved that renewable energy consumption improves India's economic growth and financial development [16].

Second, certain studies have emphasized that the renewable energy consumption negatively affects economic growth. This finding is explained by the notion that the development and use of renewable energy generate substantial economic costs, thereby causing economic burden.

Ocal and Aslan used the ARDL model and proved that the renewable energy consumption is not conducive to economic growth in Turkey [17]. Similarly, Destek found that renewable energy consumption is not conducive to India's economic growth [18]. Wang et al. used the TwoStage Least Square approach to prove that the renewable energy consumption discourages economic growth in Pakistan [19]. Khoshnevis and Bahram [20], Sasana and Ghozali [21], and Magazzino [22] asserted that renewable energy consumption will have an adverse impact on economic activities. Ozcan and Ozturk pointed out that renewable energy consumption may have detrimental effects on economic performance level [23].

Finally, the expanding research has indicated that the impact of renewable energy consumption on economic growth may change in different situations. Thus, a nonlinear relationship exists between the renewable energy consumption and economic growth. 
Destek and Aslan investigated the impact of renewable energy consumption on the economic growth of 17 countries. They emphasized that renewable energy consumption can merely promote economic growth in Peru, Greece, and South Korea [24]. Narayan and Doytch proved that renewable energy consumption in low- and middle-income countries can promote economic growth. However, renewable energy consumption in countries with high-income level exhibits no impact on economic growth [25]. Xie et al. used the data from seven countries with high energy consumption levels and demonstrated a nonlinear relationship between renewable energy consumption and economic growth. Furthermore, they pointed out that technological upgrading can stimulate the renewable energy consumption to positively affect economic growth [26]. Destek and Sinha found the U-shaped relationship between renewable energy consumption and economic growth among 24 OECD countries [27].

Although scholars have focused on the relationship between renewable energy consumption and economic growth in the relative studies, they failed to analyze the relationship between the renewable energy consumption and green economic development. As one of the keys to achieving sustainable development, green economic development should be valued.

Several studies have proved that technological advancement can stimulate the positive effects of renewable energy consumption on economic development. If technological advancement can stimulate the renewable energy consumption, will it exhibit a positive effect on green economic development? Which technological advancement approaches can coordinate the relationship between renewable energy consumption and green economic development? Should we develop a new and high-tech solution or improve existing ones? This present study responds to the requirements of sustainable development and analyzes the possibility of coordinating the relationship between renewable energy consumption and green economic development through technological advancement.

\section{Theoretical analysis and assumptions}

\section{Threshold effect of renewable energy consumption scale}

This paper believes that due to the intertemporal effect of renewable energy consumption, the scale of renewable energy consumption affects the relationship between renewable energy consumption and green economic development. The intertemporal effect of renewable energy consumption refers to the fact that the advantages of renewable energy cannot be reflected in a short period of time, especially in the early stage of renewable energy development. This is because, in the early stages of renewable energy development, due to technological mismatches, the high cost of renewable energy use is not conducive to green economic development. However, as the renewable energy consumption reaches a certain scale, the development of renewable energy technologies has reduced the cost of using renewable energy. At this time, the intertemporal effect of renewable energy is also weakened, and renewable energy consumption has shown a positive impact on green economic development.

In addition, due to the existing technical conditions, this paper believes that when the scale of renewable energy consumption exceeds a certain range, it may also hinder green economic development. Since fossil energy has been widely used earlier, compared with renewable energy, fossil energy better complements the needs of the production process under the existing technical conditions. With the expansion of renewable energy consumption, the proportion of fossil energy consumption has decreased. If the proportion of fossil energy consumption is reduced to a certain level, at this time, although renewable energy can reduce pollution emissions, it may not be conducive to production efficiency, thereby reducing the level of green economic development. Accordingly, this study proposes

Assumption 1 Under the existing technical conditions, renewable energy consumption can only promote green economic development if it is in "appropriate range." Too high and too low levels of renewable energy consumption are not conducive to green economic development.

\section{Threshold effect of technological advancement}

This study believes that the inadequacy of technical conditions and renewable energy production methods is an important reason for the uncoordinated relationship between renewable energy consumption and green economic development. Technology is often considered the key to increasing productivity. Because the development and use of renewable energy require high-tech support, existing technical conditions may restrict the consumption of renewable energy and have a negative effect on green economic development, especially when the proportion of renewable energy consumption exceeds a certain range. Therefore, we need to coordinate the relationship between renewable energy consumption and green economic development through technological advancement.

This paper hopes to further determine whether to develop new technologies or improve existing ones. Technological innovation should be the key to coordinating the relationship between renewable energy 
consumption and green economic development. As mentioned above, renewable energy cannot be separated from high-tech support. When the technological innovation capacity is insufficient, not only the development of renewable energy needs to pay more costs, but renewable energy also has lower efficiency. At this time, although renewable energy consumption reduced pollution emissions, it also reduced the level of green economic development. Conversely, strengthening technological innovation capabilities can help coordinate the relationship between renewable energy consumption and green economic development by increasing the cost-effectiveness of renewable energy.

Improving existing technologies may not affect the relationship between renewable energy consumption and green economic development. This is because the existing production technology is more suitable for fossil energy rather than renewable energy. Therefore, although the improvement of the existing technology may also increase production efficiency to a certain extent, it is impossible to coordinate the relationship between renewable energy consumption and green economic development. In addition, due to the limited technical resources available in society, if a large amount of technical resources is used to improve existing technologies instead of the development of new technologies, then it is not even conducive to coordinating the relationship between renewable energy consumption and green economic development. Accordingly, this study proposes

Assumption 2a Developing new technologies can coordinate the relationship between renewable energy consumption and green economic development.

Assumption 2b Improving existing technologies cannot coordinate the relationship between renewable energy consumption and green economic development. Excessive improvement of existing technologies will even destroy the relationship between renewable energy consumption and green economic development.

\section{Threshold effect of fossil energy dependence}

We believe that Path-Dependence [28] also exists in energy consumption, which means that once people are accustomed to a specific way of energy consumption (whether it is fossil energy or renewable energy), they may become dependent on this energy consumption. Therefore, the dependence of GDP on fossil energy is related to the relationship between renewable energy consumption and green economic development. If a country's GDP is less dependent on fossil energy, although the development and use of renewable energy has changed the production mode, it will not reduce production efficiency, and with the reduction of pollution emissions, it has promoted green economic development. Conversely, if a country's GDP is highly dependent on fossil energy and even energy consumption is "locked in" to fossil energy, although renewable energy consumption reduces pollution emissions, it also reduces production efficiency, which is not conducive to promoting green economic development. Accordingly, this study proposes

Assumption 3 Reducing the dependence of GDP on fossil energy can help coordinate the relationship between renewable energy consumption and green economic development.

\section{Threshold effect of economic development stage}

Intertemporal effects exist not only in renewable energy consumption, but also in economic development. The intertemporal impact of economic development refers to the different stages of economic development. Batlle [29] pointed out that the cost of developing and using renewable energy is high and the government should provide preferential policies to reduce these costs. When the economy is in depression, the reduction in government revenue prevents the government from providing effective preferential policies for renewable energy. At this time, the cost of developing and using renewable energy cannot be reduced. Therefore, when the level of economic development is weak, expanding the consumption of renewable energy has high economic costs and is not conducive to green economic development. Conversely, when the economic development is in the upsurge stage, the government has the economic strength to support the development of renewable energy. Preferential policies have reduced the cost of renewable energy development and use. In addition, people in countries with high levels of economic development also have high requirements for the living environment, so they use renewable energy spontaneously, which is conducive to the development of renewable energy industry. Accordingly, this study proposes

Assumption 4 Economic development level will affect the relationship between renewable energy consumption and green economic development.

It is worth noting that no matter what stage of economic development, we should continue to develop renewable energy, even in the depression. As the OECD points out, it is not wise to return to the traditional development mode. Sustainable development is the theme of future development. Countries should not reduce the 
demand for renewable energy consumption. Instead, they should find ways to coordinate renewable energy consumption with green economic growth.

\section{Methodology}

\section{Data and measurements}

Following the OECD definition of green economic development, we believe that green economic development requires the reduction of pollution emissions and the increase in production efficiency while promoting economic growth. Therefore, this present study uses the SBM-GML approach with desired and undesired outputs to measure the increase in green total factor productivity among the 27 member states of the EU and expresses the level of green economic development.

Combining with the study of Luenberger [30], Chung et al. [31] applied the direction distance function to the Malmquist approach. He used the Malmquist-Luenberger index based on Slacks-Based Measure (SBM-ML) approach to measure the total factor productivity with undesired outputs. Using the ML approach, Yoruk and Zaim [32], Kumar [33], and Feng and Apostolos [34] used GDP as the desired output and pollutant emissions as the undesired output. Oh [35] built the global MalmquistLuenberger (GML) approach based on SBM-ML approach. Compared with the SBM-ML approach, the SBM-GML approach can address the unsolvable problem of linear programming.

This paper uses the SBM-GML approach to measure the green economic development (Green) levels among the $27 \mathrm{EU}$ member countries. The desired output is GDP, whereas the undesired output is carbon dioxide emission. Moreover, the input factors include capital stock, total labor force, and total energy consumption. Table 1 presents the green economic development index evaluation system.

Through the SBM-GML approach, we can obtain the green economic development level of each country. In fact, when using the SBM-GML method, we can treat technology factors as an "intangible element" that has an impact on output in addition to the input factors, because it does not actually exist in the index evaluation system. Technology factors include the technological progress rate and technical efficiency. The technological progress rate reflects the ability of technological innovation by indicating the changes of the production frontier. Technical efficiency reflects the existing technology production efficiency by comparing the actual output level with the theoretical optimal output level. Therefore, we can obtain the technical progress rate and technical efficiency by decomposing the result of SBM-GML.

Independent variable Renewable energy consumption (REC) indicates renewable energy consumption (\% of total energy consumption). In the statistics of renewable energy consumption, this paper believes that there is no doubt that the water cycle process is infinite, and water resources can be replenished through atmospheric precipitation after being used. However, unlike other renewable energy sources, the amount and rate of natural regeneration of water resources are limited. In addition, due to the limited storage of global water resources, water conservation needs to be emphasized, especially in some water-scarce countries. From the perspective of hydrodynamic balance, if the amount of water used in a period exceeds the recharge amount, the water balance will be destroyed, and a series of environmental problems will become more prominent. Therefore, the statistics of renewable energy consumption in this paper do not include hydropower consumption. This paper draws on the practice of the 2019 BP Statistical Review of World Energy to count renewable energy consumption, which is based on gross generation from renewable sources, including wind, geothermal, solar, biomass and waste, and not accounting for cross-border electricity supply.

Threshold variable Technological innovation (TC) is a decomposition term of the Global Malmquist-Luenberger index that indicates the technological progress rate. Technical efficiency (EC) is a decomposition term of the Global Malmquist-Luenberger index that denotes the existing technology production efficiency. Fossil energy dependence (FED) refers to the contribution of fossil energy consumption to GDP, which is indicated by fossil energy consumption (\% of GDP). GDP per capita (PGDP) indicates different stages of economic development. Due to the large value range of PGDP, to prevent the existence of heteroscedasticity, this study performs

Table 1 Green economic development Index Evaluation System

\begin{tabular}{lll}
\hline Category & Variable & Description \\
\hline Input factor & Capital stock & Total capital formation of the countries \\
& Total labor force & Total labor force of the countries \\
Total energy consumption & Total energy consumption of the countries \\
Undesired output & GDP & Gross Domestic Product of the countries \\
\hline
\end{tabular}


logarithmic processing on PGDP. We also use REC as the threshold variable to analyze the optimal range of renewable energy consumption that promotes green economic development under the existing technology conditions.

Controlled variable The population density (DEN) is measured by the logarithm of the number of people per kilometer of land area. Since population density is closely related to resources and the economy, we believe that population density will also affect the green economic development. Economic theory takes the labor force represented by population density as an important variable to promote economic development [36]. However, at the same time, the increase in population density may cause an increase in the consumption of energy, and an increase in emissions of pollutants such as the atmosphere and solid waste [37]. Therefore, when we study the green economic development, we use population density as a control variable.

Government intervention (GOV) is measured by the total government financial expenditure (\% of GDP). The government can make up for the shortcomings of the market through appropriate administrative intervention and enhance the standardization of the market mechanism through administrative means to guide the direction of economic development [38]. In addition, government intervention can guide the adjustment of the industrial structure and gradually eliminate backward polluting industries [39], thereby promoting the green economic development.

Unemployment rate (UNE) is measured by the total number of unemployed (\% of total labor). The unemployment rate reflects the total number of unemployment in a country. This study points out that when studying the relationship between renewable energy consumption and green economic development, the unemployment rate should be used as a control variable. Rising unemployment will inevitably have an adverse impact on economic development [40]. The products and services obtained by workers in economic activities are lost as the unemployment rate rises [41]. If the economy is under-employed, it indicates that the unemployment rate has a great negative impact on social productivity.

The empirical analysis employs the annual panel data of the $27 \mathrm{EU}$ member countries (excluding the Republic of Malta) from 2008 to 2017. All data are gathered from the 2019 BP Statistical Review of World Energy and World Bank WDI Database. Table 2 reports the summary statistics of the variables.

The Green economic development Index in this study is obtained by adding the undesired output through the directional distance function in the process of calculating total factor productivity (TFP). During calculation, the Green economic development index is obtained by comparing the growth rate of TFP in a specific period and the previous period. Therefore, the Green economic development Index must be greater than 0 . When the Green economic development Index is greater than 0 but less than 1 , it indicates that the level of green economic development is decreasing. When the Green economic development Index is greater than 1, it indicates that the level of green economic development is increasing. The calculation process of Technological Innovation (TC) and Technical Efficiency (EC) is similar to the Green economic development Index, and they are decomposition terms in the calculation of total factor productivity. Therefore, the ranges of Technological Innovation (TC) and Technical Efficiency (EC) are the same as those of Green economic development index.

\section{Modeling}

This study constructs the threshold models based on the threshold regression proposed by Hansen [42]. The threshold model aids in investigating whether developing new technologies or improving existing technologies can affect

Table 2 Statistical description of variables

\begin{tabular}{|c|c|c|c|c|c|}
\hline Variables (units) & Observation & Average value & $\begin{array}{l}\text { Standard } \\
\text { deviation }\end{array}$ & Minimum value & Maximum value \\
\hline Green (-) & 270 & 1.022 & 0.138 & 0.661 & 1.674 \\
\hline REC (\%) & 270 & 3.387 & 3.711 & 0.003 & 20.439 \\
\hline$T C(-)$ & 270 & 1.025 & 0.187 & 0.439 & 1.819 \\
\hline$E C(-)$ & 270 & 1.012 & 0.124 & 0.617 & 1.661 \\
\hline $\begin{array}{l}\text { FED/(million toe/billions of } \\
\text { US dollars) }\end{array}$ & 270 & 0.106 & 0.056 & 0.034 & 0.312 \\
\hline$P G D P$ & 270 & 10.214 & 0.650 & 8.831 & 11.686 \\
\hline DEN/(people) & 270 & 4.612 & 0.774 & 2.861 & 6.231 \\
\hline GOV/(\%) & 270 & 38.991 & 7.068 & 17.616 & 62.381 \\
\hline UNE (\%) & 270 & 9.496 & 4.653 & 2.750 & 27.466 \\
\hline
\end{tabular}


the relationship between renewable energy consumption and green economic development.

The construction process of the threshold models is as follows:

$$
Y_{i t}=\mu_{i t}+\beta_{1}^{\prime} x_{i t} \mathrm{I}\left(q_{i t} \leq \gamma\right)+\beta_{2}^{\prime} x_{i t} \mathrm{I}\left(q_{i t}>\gamma\right)+e_{i t} .
$$

In formula (1), where $i$ represents sample countries; $t$ denotes the year; $Y_{i t}$ pertains to the dependent variable; $x_{i t}$ refers to the independent variable; $q_{i t}$ represents the threshold variable; $\gamma$ stands for the threshold value to be estimated; $e_{i t}$ denotes a random disturbance item; $\mu_{i t}$ is used to remove individual-specific means; $\beta_{1}^{\prime}$ and $\beta_{2}^{\prime}$ are coefficients to be estimated for independent variable; $e_{i t}$ refers to a group of control variables; $I($.) pertains to the indicator function: when the condition in parentheses is satisfied, it is taken as 1 , otherwise, it is taken as 0 .

For a given threshold value, we can estimate the model using the ordinary least square (OLS) regression method to obtain the sum of the squared errors, while the sum of the squared errors calculations is as follows:

$$
\begin{aligned}
S_{1}\left(\gamma_{0}\right) & =\hat{e}^{*}(\gamma)^{\prime} \hat{e}^{*}(\gamma) \\
& =Y^{* \prime}\left(1-x^{*}(\gamma)^{\prime}\left(x^{*}(\gamma)^{\prime} x^{*}(\gamma)\right)^{-1} x^{*}(\gamma)\right) Y^{*}
\end{aligned}
$$

where $Y_{i t}^{*}=Y_{i t}-\bar{Y}_{i t}, x_{i t}^{*}=x_{i t}-\bar{x}_{i t}$, and $e_{i t}^{*}=e_{i t}-\bar{e}_{i t}$.

$\gamma$ can be estimated by least squares and can be easily determined by minimization of the concentrated sum of the squared errors (2). The least squares estimators are as follows:

$$
\hat{\gamma}=\arg \min _{\gamma} S_{1}\left(\gamma_{0}\right) .
$$

After $\hat{\gamma}$ is obtained, the residual variance is as follows:

$$
\hat{\sigma}^{2}=\frac{1}{n(T-1)} \hat{e}^{*} \hat{e}^{*}=\frac{1}{n(T-1)} S_{1}(\hat{\gamma}) .
$$

Only one $\gamma$ value exists in formula (1); thus, formula (1) is a single threshold model. If multiple threshold values are present for the threshold variable, then we can construct a panel threshold model with multiple threshold values. Thus, formula (2) is expressed as

$$
\begin{aligned}
Y_{i t}= & \mu_{i}+\beta_{0}^{\prime} z_{i t}+\beta_{1}^{\prime} \operatorname{green}_{i t} I\left(q_{i t} \leq \gamma_{1}\right) \\
& +\beta_{2}^{\prime} \text { green }_{i t} I\left(\gamma_{1}<q_{i t} \leq \gamma_{2}\right) \\
& +\beta_{3}^{\prime} \text { green }_{i t} I\left(q_{i t}>\gamma_{2}\right)+e_{i t} .
\end{aligned}
$$

The threshold models above can be implemented in Stata14.

\section{Results and discussion}

The Hausman test is initially employed to detect the endogeneity between Green and REC. Table 3 reports the test results. Evidently, given that the error coefficient is insignificant, we cannot reject the null hypothesis of endogeneity. Therefore, the threshold model can provide robust results without endogeneity.

The Bootstrap approach is used to calculate the threshold value in this study. All the data are repeatedly sampled for 300 times through the repeated Bootstrap approach to obtain robust values. Tables 4 and 5 indicate the calculation results of the threshold value.

We performed a significant test on the threshold values, and the test results are shown in Table 4. Evidently, when REC, TC and PGDP are used as the threshold variables, two threshold values pass the significance test. In addition, when EC and FED are used as the threshold variables, only a threshold value passes the significance test.

We calculate the corresponding threshold values after the number of thresholds is determined. Table 5 presents that the threshold values of the REC are 0.67 and 10.87; the threshold values of the TC are 0.75 and 1.23; the threshold value of the EC is 1.03; the threshold value of the FED is 0.13 ; and the threshold values of the PGDP are 9.10 and 9.17.

The impact of renewable energy consumption on green economic development is subsequently analyzed through the threshold regression models. Table 6 reports the results. Models 1, 2, 3, 4 and 5 indicate that REC, TC, EC, FED and PGDP are used as threshold variables.

The following conclusions are derived from the empirical results of Models 1, 2, 3 and 4.

1. Model 1 reveals the inverted $\mathrm{N}$-shaped relationship between renewable energy consumption and green economic development under the existing technical conditions. Assumption 1 is confirmed. In particular, when the REC level is lower than 0.67 , the renewable energy consumption exhibits a significant negative impact on green economic development, while the marginal coefficient is -1.649 . The REC level that is higher than 0.67 but lower than 10.87 indicates that the renewable energy consumption has a significant positive impact on green economic development,

Table 3 Threshold value estimates

\begin{tabular}{lll} 
Coefficient & $\boldsymbol{p}$ value & Ho: no endogeneity is evident \\
\hline REC 2.87 & 0.579 & $\begin{array}{c}\text { The null hypothesis of endogeneity was not } \\
\text { rejected }\end{array}$
\end{tabular}


Table 4 Test for threshold value

\begin{tabular}{|c|c|c|c|c|c|c|c|c|c|c|c|c|}
\hline \multirow[t]{2}{*}{ Variables } & \multicolumn{6}{|c|}{ Test for single threshold value } & \multicolumn{6}{|c|}{ Test for double threshold value } \\
\hline & F value & $p$ value & BS & $10 \%$ & $5 \%$ & $1 \%$ & $F$ value & $p$ value & BS & $10 \%$ & $5 \%$ & $1 \%$ \\
\hline REC & 16.87 & 0.00 & 300 & 8.01 & 9.81 & 12.64 & 4.34 & 0.08 & 300 & 12.81 & 16.54 & 21.11 \\
\hline$T C$ & 55.49 & 0.00 & 300 & 10.53 & 13.79 & 18.47 & 48.15 & 0.00 & 300 & 10.13 & 13.11 & 17.08 \\
\hline EC & 12.10 & 0.03 & 300 & 7.21 & 9.15 & 14.56 & 1.38 & 0.91 & 300 & 9.72 & 12.17 & 18.75 \\
\hline FED & 16.90 & 0.01 & 300 & 10.15 & 12.09 & 16.16 & 8.12 & 0.13 & 300 & 9.81 & 12.18 & 15.14 \\
\hline$P G D P$ & 17.15 & 0.00 & 300 & 7.81 & 10.34 & 14.17 & 11.37 & 0.03 & 300 & 8.63 & 10.45 & 13.35 \\
\hline
\end{tabular}

Table 5 Calculation result of threshold values

\begin{tabular}{|c|c|c|}
\hline Variables & $\begin{array}{l}\text { Threshold value } 1 \text { [lower } \\
\text { upper] }\end{array}$ & $\begin{array}{l}\text { Threshold value } \\
2 \text { [lower upper] }\end{array}$ \\
\hline REC & 0.67 [0.29 0.83$]$ & 10.87 [10.84 10.88] \\
\hline TC & $0.75[0.730 .77]$ & $1.23\left[\begin{array}{ll}1.20 & 1.24\end{array}\right]$ \\
\hline$E C$ & 1.03 [1.01 1.05] & \\
\hline FED & $0.13[0.120 .14]$ & \\
\hline PGDP & 9.10 [9.03 9.12] & 9.17 [8.85 9.21] \\
\hline
\end{tabular}

and the marginal coefficient is 0.033. By contrast, when the REC level is higher than 10.87, the renewable energy consumption exhibits a significant negative impact on green economic development, while the marginal coefficient is -0.003 .

When the degree of renewable energy consumption is less than 0.67 , the scale of renewable energy consumption is small. Zwaan and Rabl [43], Kobos et al. [44], and Klitkou et al. [45] indicated that if energy consumption reaches a certain scale, then it can reduce the cost of energy use. That is, if renew- able energy consumption fails to reach a certain scale, then the cost of developing and using renewable energy tends to be high. Thus, the low degree of renewable energy consumption generates great economic costs. At this point, the renewable energy consumption has reduced pollution emissions, but it is not conducive to green economic development.

The increased intensity of renewable energy consumption indicates that when the renewable energy consumption degree is greater than 0.67 and less than 10.87, the renewable energy consumption has reached a certain scale. Thus, the cost of renewable energy development and use is reduced. At this point, the renewable energy consumption has reduced the burden on the economy, which can promote green economic development.

The increasing proportion of renewable energy consumption indicates that when its degree exceeds 10.87 , the proportion of renewable energy consumption increases while the proportion of fossil energy consumption decreases. Since fossil energy has been

Table 6 Threshold model regression results

\begin{tabular}{|c|c|c|c|c|c|c|}
\hline \multirow[t]{2}{*}{ Green } & \multirow[t]{2}{*}{ Fixed effect model } & \multicolumn{5}{|c|}{ Panel threshold model } \\
\hline & & Model 1 & Model 2 & Model 3 & Model 4 & Model 5 \\
\hline \multirow[t]{3}{*}{$R E C$} & $0.006^{* *}(0.004)$ & $\begin{array}{l}-1.649 * *(0.014) \\
(R E C \leq 0.67)\end{array}$ & $\begin{array}{l}-0.109^{* * *}(0.000) \\
(T C \leq 0.75)\end{array}$ & $\begin{array}{l}-0.053(0.330) \\
(E C \leq 1.03)\end{array}$ & $\begin{array}{l}0.054^{* *}(0.011) \\
(F E D \leq 0.13)\end{array}$ & $\begin{array}{l}-0.006^{*}(0.074) \\
(P G D P \leq 9.10)\end{array}$ \\
\hline & & $\begin{array}{l}0.033^{* * *}(0.000) \\
(0.67<R E C \leq 10.87)\end{array}$ & $\begin{array}{l}-0.008^{*}(0.077) \\
(0.75<T C \leq 1.23)\end{array}$ & $\begin{array}{l}-0.142^{* * *} \\
(E C>1.03)\end{array}$ & $\begin{array}{l}-0.029^{* * *}(0.004) \\
(F E D>0.13)\end{array}$ & $\begin{array}{l}0.005^{*}(0.082) \\
(9.10<P G D P \leq 9.17)\end{array}$ \\
\hline & & $\begin{array}{l}-0.003^{* * *}(0.001) \\
(R E C>10.87)\end{array}$ & $\begin{array}{l}0.028^{* * *}(0.000) \\
(T C>1.23)\end{array}$ & & & $\begin{array}{l}0.021^{* *}(0.043) \\
(P G D P>9.17)\end{array}$ \\
\hline DEN & $-0.158^{* * *}(0.000)$ & $-0.198^{* * *}(0.000)$ & $-0.141^{* *}(0.048)$ & $-0.196^{* *}(0.037)$ & $-0.153^{* *}(0.032)$ & $-0.141^{*}(0.052)$ \\
\hline GOV & $0.002^{* * *}(0.000)$ & $0.002 *(0.076)$ & $0.00^{* * *}(0.000)$ & $0.003^{*}(0.065)$ & $0.001^{* * *}(0.000)$ & $0.002^{* *}(0.027)$ \\
\hline UNE & $-0.004^{*}(0.076)$ & $-0.003(0.370)$ & $-0.002^{* * *}(0.001)$ & $-0.003^{* * *}(0.000)$ & $-0.002^{* *}(0.028)$ & $-0.003^{* * *}(0.000)$ \\
\hline Cons & $1.514^{* * *}(0.000)$ & $2.312^{* * *}(0.000)$ & $2.454^{* * *}(0.000)$ & $2.043^{* * *}(0.000)$ & $1.923^{* * *}(0.000)$ & 0.319 \\
\hline obs & 270 & 270 & 270 & 270 & 270 & 270 \\
\hline F test & 34.46 & 35.47 & 27.84 & 32.56 & 34.11 & 30.52 \\
\hline
\end{tabular}

*** represents that the regression result is significant at the $1 \%$ level; ${ }^{*}$ represents that the regression result is significant at the $5 \%$ level; and ${ }^{*}$ represents that the regression result is significant at the $10 \%$ level 
widely used earlier; therefore, compared with renewable energy, fossil energy better complements the needs of the production process under the existing technical conditions. Therefore, if the proportion of fossil energy consumption is reduced to a certain extent under the existing technical conditions, then production efficiency and resource utilization rates will be reduced. At this point, the renewable energy consumption is conducive to green economic development.

In summary, under the current technical conditions, the renewable energy consumption can only promote green economic development when it is within the range of $0.67-10.87$.

2. Model 2 shows that when the TC level is lower than 0.75 , the renewable energy consumption exhibits a significant negative impact on green economic development, while the marginal coefficient is -0.109 . Notably, the TC level that is higher than 0.75 but lower than 1.23 weakens the negative impact of the renewable energy consumption on green economic development, and the marginal coefficient is -0.008 . However, when the TC level is higher than 1.23, the renewable energy consumption has a significant positive impact on green economic development, while the marginal coefficient is 0.028 . Assumption 2a is confirmed.

The results of Model 2 prove that technological innovation can stimulate the positive effect of renewable energy consumption on green economic development. The development and use of renewable energy require new and high-tech support [46]. Thus, when the technological innovation capability is insufficient, renewable energy fails to adapt to the existing production technology. At this point, although the renewable energy consumption reduces pollution emissions, it also reduces production efficiency and is not conducive to green economic development. The increase of technological innovation capability has supported renewable energy by improving its costeffective use. Thus, the renewable energy consumption exhibits a positive impact on green economic development.

In summary, new and high-tech support is the key to improving the efficiency of renewable energy use. Enhancing technological innovation capabilities can help mediate the relationship between renewable energy consumption and green economic development.

3. Model 3 shows that when the EC level is lower than 1.03 , the regression coefficient of renewable energy consumption for green economic development fails the significant test. Therefore, improving existing technology will not affect the relationship between renewable energy consumption and green economic development. By contrast, when the EC level is higher than 1.03, the renewable energy consumption reveals a significant negative impact on green economic development, while the marginal coefficient is -0.142 . Assumption $2 b$ is confirmed.

This finding occurs because the existing production technology is more suitable for fossil energy than for renewable energy. Although the improvement of the existing technology can effectively improve the efficient use of fossil energy, it will not affect renewable energy. Therefore, appropriate improvements to existing technology will not affect the relationship between the renewable energy consumption and green economic development. However, excessive improvements to existing technologies consume a substantial amount of technical funds, personnel, and equipment. Thus, great economic costs are required, and a crowding out effect on technological innovation is present. Improving existing technology cannot mediate the relationship between renewable energy consumption and green economic development.

In summary, appropriate improvements to existing technologies fail to mediate the relationship between renewable energy consumption and green economic development. Furthermore, excessive improvements to existing technologies may consequently yield negative impact in the relationship between renewable energy consumption and green economic development.

4. This study also investigates whether the degree of fossil energy dependence affects the relationship between renewable energy consumption and green economic development. Assumption 3 is confirmed. Model 4 reveals that when the FED level is lower than 0.13 , the renewable energy consumption exhibits a significant positive impact on green economic development, while the marginal coefficient is 0.054 . By contrast, when the FED level is higher than 0.13, the renewable energy consumption has a significant negative impact on green economic development, and the marginal coefficient is -0.029 .

The dependence of GDP on fossil energy is related to the relationship between renewable energy consumption and green economic development based on path-dependence theory in energy consumption. Path-dependence theory posits that when the country or region's energy consumption is "locked" to fossil energy, its GDP exhibits high dependence on fossil energy consumption. Thus, fossil energy consumption promotes economic growth, which 
is similar to "inertia." In countries or regions where the degree of fossil energy dependence is high, the renewable energy consumption fails to induce economic growth. Therefore, although pollution emissions are reduced, green economic development lacks improvement.

In summary, the relationship between renewable energy consumption and green economic development can be mediated by reducing the GDP's dependence on fossil fuels.

5. Model 5 shows that the stage of economic development will impact the effect of renewable energy on green economic development. Assumption 4 is confirmed. When PGDP is less than 9.10, the regression coefficient of REC is -0.006 . However, when PGDP exceeds 9.10 but is less than 9.17 , the regression coefficient of REC becomes positive, which is 0.005 . As PGDP continues to increase, when GDP exceeds 9.17, the regression coefficient of REC increases to 0.021 .

Empirical results show that the stage of economic development will affect the relationship between renewable energy consumption and green economic development. In countries with low levels of economic development, the government cannot provide preferential policies for the development of renewable energy, resulting in high renewable energy usage costs that are not conducive to green economic development. In addition, countries with low levels of economic development are also unable to provide advanced technologies for renewable energy, resulting in the use efficiency of renewable energy cannot be improved. Conversely, countries with a high level of economic development can reduce the cost of renewable energy development through corresponding preferential policies, and provide advanced technologies for improving the efficiency of renewable energy use, thereby helping to coordinate the relationship between renewable energy consumption and green economic development.

6. Although from the perspective of threshold effect, the impact of renewable energy consumption on green economic development is non-linear. In some cases, renewable energy consumption may even have a negative impact on green economic development. However, the 27-member fixed-effects model shows that without considering the threshold effect, the overall increase in renewable energy consumption in the EU can promote green economic development.

7. We selected 9 representative countries and divided them into 3 groups to determine whether the empirical results are robust. The first group is countries with a high levels of renewable energy consumption
(\% of total energy consumption), including Sweden, Austria and Latvia. The second group is countries with moderate levels of renewable energy consumption (\% of total energy consumption), including Germany, France and Italy. The third group is countries with low levels of renewable energy consumption (\% of total energy consumption), including Netherlands, Luxembourg and Belgium.

The results in Table 7 are the same as those of Model 1 , demonstrating the robustness of the threshold regression. The results of group regression also show that countries with high levels of renewable energy consumption (\% of total energy consumption) such as Sweden, Austria and Latvia need to pay attention to coordinating the relationship between renewable energy consumption and green economic development. Under current technological conditions, renewable energy consumption may not be conducive to green economic development. In these countries, technological innovations related to renewable energy need to be valued.

In addition, although the level of renewable energy consumption in the second group of countries is in the "appropriate range", the proportion of renewable energy consumption will continue to increase in the context of sustainable development. Therefore, these countries should also pay attention to the technological innovation of renewable energy in advance to prevent the technological level from not adapting to the development and utilization of renewable energy in the future.

For the third group of countries, the relationship between renewable energy consumption and green economic development is not coordinated because the development and use of renewable energy have not reached a certain scale. Renewable energy is inseparable from sustainable development. Therefore, these countries should actively adjust their industrial structures and promote the environmentally friendly industries to increase the renewable energy consumption, while focusing on the increase in technological innovation capabilities.

Table 7 Robustness test

\begin{tabular}{lllll}
\hline & REC & DEN & GOV & UNE \\
\hline Group 1 & $-0.032^{* *}$ & $-0.382^{*}$ & 0.001 & $0.002^{* *}$ \\
Group 2 & $0.017^{* * *}$ & $-1.434^{* *}$ & $0.007^{* * *}$ & 0.014 \\
Group 3 & $-0.091^{* *}$ & $-0.70^{*}$ & $0.003^{*}$ & $0.005^{* *}$
\end{tabular}

*** represents that the regression result is significant at the $1 \%$ level; ** represents that the regression result is significant at the $5 \%$ level; and * represents that the regression result is significant at the $10 \%$ level 
8. By analyzing the regression results of the controlled variables, we find that population density (DEN) has a negative impact on the green economic development. This shows that although a higher level of population density has brought labor for economic development, it will also make the problems of resource exhaustion and environmental pollution more prominent. Taken together, population density is not conducive to green economic growth. At this time, the importance of renewable energy consumption is more prominent. How to coordinate the relationship between renewable energy consumption and green economic development should be paid more attentions.

Government intervention (GOV) has a positive impact on green economic development. This shows that to realize the green economic development, the government can guide the adjustment of industrial structure through appropriate policies, and gradually phase out the backward environmentally polluting industries.

The unemployment rate (UNE) has a negative impact on green economic development. Unemployment rate can judge the employment situation of all working people in a certain period of time. A rising unemployment rate in a country represents a lack of social productivity. At this time, economic development is in a slowdown and recession stage, and the level of green economic development will also decline.

\section{Conclusions and recommendations}

This study measures the green economic development level among the $27 \mathrm{EU}$ member countries through the SBM-GML approach. In addition, this study identifies the technological advancement approaches that can mediate the relationship between renewable energy consumption and green economic development. Thus, the following conclusions are obtained, and corresponding policy recommendations are proposed.

1. Under the existing technical conditions, the degree of renewable energy consumption can only promote green economic development in the interval of 0.6710.87. That is, the renewable energy consumption is subject to the existing technical conditions. When the proportion of renewable energy consumption is less than $0.67 \%$, the renewable energy consumption hinders green economic development because smallscale renewable energy development and use cost is a substantial amount. Renewable energy reduces pollution emissions, but it is not conducive to productivity and economic growth. Similarly, when the proportion of renewable energy consumption exceeds
$10.87 \%$, the renewable energy consumption fails to induce green economic development. This finding is supported by the fact that renewable energy consumption exhibits a crowding effect on fossil energy consumption, and existing production technologies are more suitable for fossil energy than for renewable energy. Notably, no matter whether it is a country with a proportion of renewable energy consumption in the "appropriate range" under current technological conditions, it is worth focusing on increasing the technological level to coordinate the relationship between renewable energy consumption and green economic development. As the OECD points out, we must look to the future and find new ways to ensure growth and development. It is not wise to return to the traditional development mode. Sustainable development is the theme of future development. Countries should not reduce the demand for renewable energy even when renewable energy consumption is inconsistent with production efficiency. Instead, they should continue to actively develop the renewable energy industry. Therefore, countries should also actively develop new technologies to avoid situations that are not conducive to green economic development as the proportion of renewable energy consumption increases, so as to make the economy develop in a green direction.

2. Increasing technological innovation capability is a key to mediate the relationship between renewable energy consumption and green economic development. Conversely, improving existing technology fails to mediate the relationship between renewable energy consumption and green economic development. Therefore, for countries where the proportion of renewable energy consumption exceeds the "appropriate range" under current technological conditions (such as the representative countries selected in Table 7: Sweden, Austria and Latvia), more attention should be paid to upgrading technological capabilities, especially the development of new technologies. From the perspective of the government, the government should increase funding for research and development and guide technology resources into the renewable energy industry. To achieve sustainable development, the government should continue to guide renewable energy consumption while providing research and development funding to prevent renewable energy consumption from unfavorable to green economic development due to technological inadequacy. From the perspective of renewable energy companies, after receiving government technology research and development funding support, companies need to actively innovate technologies, 
rather than "re-absorb" existing technologies. Especially in countries with a large proportion of renewable energy consumption, the existing technical conditions are no longer sufficient to improve the efficiency of renewable energy use. These countries should actively develop new technologies to improve the efficiency of renewable energy use, so as to ensure that renewable energy consumption can promote green economic growth.

Increasing technological innovation capabilities is equally important to other countries. It would be unwise to return to an extensive economic development model. The proportion of renewable energy consumption will continue to increase in the future. In countries where the proportion of renewable energy consumption is in the "appropriate range" under the current technological conditions, the development and use cost of renewable energy should be reduced by increasing the technological innovation capacity, so as to prevent the situation that is adverse to green economic development in the future when the proportion of renewable energy consumption is increasing. Countries with a low proportion of renewable energy consumption should also increase the level of renewable energy consumption and technological innovation capabilities to achieve sustainable development.

3. The relationship between renewable energy consumption and green economic development can also be mediated by reducing the GDP's dependence on fossil fuels. For countries with a high dependence on fossil energy, the government should actively promote the optimization of the energy industry structure and restrict high-polluting industries. On the one hand, the government should guide funds into green industries such as renewable energy industries, energy-saving and environmental protection industries. The government should also focus on long-term investment in renewable energy research and development to accelerate the continuous development of new technologies and new equipment, so as to provide a suitable development environment for the renewable energy industry. On the other hand, banks can appropriately reduce the lending rates through the credit rationing system to promote the development of the renewable energy industry and transform the industrial structure to a green and lowcarbon direction. By supporting the development of resource-saving and environmentally friendly industries, the government has made the industrial structure green, thereby reducing the dependence of GDP on fossil energy. In addition, countries that are less dependent on fossil energy should continue to domi- nate eco-environmentally friendly industries, further enhance the technological innovation capability of renewable energy industries, and formulate preferential policies to support the development of renewable energy industry.

4. The stage of economic development might impact the effect of renewable energy consumption on green economic development, especially in countries with relatively low levels of economic development, renewable energy consumption may even have a negative impact on green economic development. However, this result does not suggest that countries with relatively poor economic bases need to reduce their demand for renewable energy. Under the theme of sustainable development, it is unwise to return to an extensive economic growth model. Therefore, these countries need to take more proactive measures. For example, the government should focus on longterm investment in renewable energy research and development and encourage the renewable energy industry to develop new technologies rather than "reabsorb" existing technologies. In addition, the credit rationing system can also be used to guide the industrial structure to a low-carbon transition, thereby reducing the dependence of GDP on fossil energy.

\section{Abbreviations}

i: Sample countries; $t$ : Year; $Y_{i t}$ : Dependent variable; $\boldsymbol{x}_{i t}$ : Independent variable; $q_{i t}$ : Threshold variable; $\gamma$ : Threshold value to be estimated; $\boldsymbol{e}_{i t}$ : Random disturbance item; $I($.$) : Pertains to the indicator function, its value is 0$ or $1 ; Y_{i t}^{*}$ $: Y_{i t}-\bar{Y}_{i t} ; x_{i t}^{*}: x_{i t}-\bar{x}_{i t} ; e_{i t}^{*} e_{i t}-\bar{e}_{i t} ; \hat{\gamma}$ : Least squares estimation of threshold; $\hat{\gamma}=\arg \min S_{1}\left(\gamma_{0}\right) ; \hat{\sigma}^{2}$ : Residual variance;

$\hat{\sigma}^{2}=\frac{1}{n(T-1)} \hat{e}^{* \prime} \hat{e}^{*}=\frac{1}{n(T-1)} S_{1}(\hat{\gamma}) ; \beta_{1}^{\prime}$ and $\beta_{2}^{\prime}$ : Coefficients to be estimated for independent variable; GDP: Gross Domestic Product; EU: European Union; GML: Global Malmquist-Luenberger; SBM: Slacks-based measure; Green: Green economic development; REC: Renewable energy consumption; TC: Technological innovation; EC: Technical efficiency; FED: Fossil energy dependence; DEN: The population density; GOV: Government intervention; UNE: Unemployment rate.

\section{Acknowledgements}

The authors are grateful for the financial support provided by the "DoubleFirst Class"Think Tank Program of China University of Mining and Technology (No.2018WHCC01).

\section{Authors' contributions}

Conceptualization, FX and YL; methodology, FX and YL; software, FX and YL; validation, FX, YL and FG; formal analysis, FX; investigation, YL; resources, FX, YL and NW; data curation, FX, YL and NW; writing - original draft preparation, FX, $Y L$ and $F G$; writing — review and editing, FX, YL, FG and NW; visualization, FX and $Y L$; supervision, $Y L$; project administration, $F X$ and $Y L$; funding acquisition, YL. All authors read and approved the final manuscript.

\section{Funding}

This research was funded by the "Double-First Class"Think Tank Program of China University of Mining and Technology (Grant No. 2018WHCC01). 


\section{Availability of data and materials}

The datasets obtained and analyzed in the current study are available from the corresponding author on reasonable request.

\section{Ethics approval and consent to participate}

Not applicable.

\section{Consent for publication}

All authors agreed to publish the paper.

\section{Competing interests}

The authors declare that they have no competing interests.

\section{Author details}

${ }^{1}$ School of Management, China University of Mining \& Technology, Xuzhou 221116, China. ${ }^{2}$ Jiangsu Normal University Kewen College, Xuzhou 221116, China

Received: 27 January 2020 Accepted: 27 April 2020

Published online: 06 May 2020

\section{References}

1. Okafor-Yarwood I (2019) Illegal, unreported and unregulated fishing, and the complexities of the sustainable development goals (SDGs) for countries in the Gulf of Guinea. Mar Policy 99:414-422. https://doi. org/10.1016/j.marpol.2017.09.016

2. BP Statistical Review of World Energy. https://www.bp.com/en/global/ corporate/energy-economics/statistical-review-of-world-energy.html. Accessed 20 Dec 2019

3. Knopf B, Nahmmacher P, Schmid E (2015) The European renewable energy target for 2030 - an impact assessment of the electricity sector. Energy Policy 85:50-60. https://doi.org/10.1016/j.enpol.2015.05.010

4. Van Der Ploeg R, Withagen C (2013) Green growth, green paradox and the global economic crisis. Environ Innov Soc Transit 6:116-119. https:// doi.org/10.1016/j.eist.2012.11.003

5. Tugcu CT, Ozturk I, Aslan A (2012) Renewable and non-renewable energy consumption and economic growth relationship revisited: evidence from G7 countries. Energy Econ 34(6):1942-1950. https://doi.org/10.1016/j. eneco.2012.08.021

6. Lin B, Moubarak M (2014) Renewable energy consumption-economic growth nexus for China. Renew Sustain Energy Rev 40:111-117. https:// doi.org/10.1016/j.rser.2014.07.128

7. Apergis N, Payne JE (2010) Renewable energy consumption and growth in Eurasia. Energy Econ 32(6):1392-1397. https://doi.org/10.1016/j.eneco .2010.06.001

8. Sebri M, Ben-Salha O (2014) On the causal dynamics between economic growth, renewable energy consumption, $\mathrm{CO}_{2}$ emissions and trade openness: fresh evidence from BRICS countries. Renew Sustain Energy Rev 39:14-23. https://doi.org/10.1016/j.rser.2014.07.033

9. Marinas MC, Dinu M, Socol AG, Socol C (2018) Renewable energy consumption and economic growth. Causality relationship in Central and Eastern European countries. PLoS ONE. 13:e0202951. https://doi. org/10.1371/journal.pone.0202951

10. Shafiei S, Salim RA (2014) Non-renewable and renewable energy consumption and $\mathrm{CO}_{2}$ emissions in OECD countries: a comparative analysis. Energy Policy. 66:547-556. https://doi.org/10.1016/j.enpol.2013.10.064

11. Bhattacharya M, Paramati SR, Ozturk I et al (2016) The effect of renewable energy consumption on economic growth: evidence from top 38 countries. Appl Energy 162:733-741. https://doi.org/10.1016/j.apene rgy.2015.10.104

12. Paramati SR, Apergis N, Ummalla M (2018) Dynamics of renewable energy consumption and economic activities across the agriculture, industry, and service sectors: evidence in the perspective of sustainable development. Environ Sci Pollut Res 25(2):1375-1387

13. Rahman MM, Velayutham E (2020) Renewable and non-renewable energy consumption-economic growth nexus: new evidence from South Asia. Renew Energy 147:399-408. https://doi.org/10.1016/j. renene 2019.09 .007
14. Inglesi-Lotz R (2016) The impact of renewable energy consumption to economic growth: a panel data application. Energy Econ 53:58-63. https://doi.org/10.1016/j.eneco.2015.01.003

15. Alper A, Oguz O (2016) The role of renewable energy consumption in economic growth: evidence from asymmetric causality. Renew Sustain Energy Rev 60:953-959. https://doi.org/10.1016/j.rser.2016.01.123

16. Eren BM, Taspinar N, Gokmenoglu KK (2019) The impact of financial development and economic growth on renewable energy consumption: empirical analysis of India. Sci Total Environ 663:189-197. https:// doi.org/10.1016/j.scitotenv.2019.01.323

17. Ocal O, Aslan A (2013) Renewable energy consumption-economic growth nexus in Turkey. Renew Sustain Energy Rev 28:494-499. https:// doi.org/10.1016/j.rser.2013.08.036

18. Destek MA (2016) Renewable energy consumption and economic growth in newly industrialized countries: evidence from asymmetric causality test. Renew Energy 95:478-484. https://doi.org/10.1016/j. renene.2016.04.049

19. Wang Z, Zhang B, Wang B (2018) Renewable energy consumption, economic growth and human development index in Pakistan: evidence form simultaneous equation model. J Clean Prod 184:1081-1090. https ://doi.org/10.1016/j.jclepro.2018.02.260

20. Khoshnevis Yazdi S, Shakouri B (2017) Renewable energy, nonrenewable energy consumption, and economic growth. Energy Sources Part B 12(12):1038-1045. https://doi.org/10.1080/15567249.2017.1316795

21. Sasana H, Ghozali I (2017) The impact of fossil and renewable energy consumption on the economic growth in Brazil, Russia, India, China and South Africa. Int J Energy Econ Policy. 7(3):194-200

22. Magazzino C (2017) Renewable energy consumption-economic growth nexus in Italy. Int J Energy Econ Policy. 7(6):119-127

23. Ozcan B, Ozturk I (2019) Renewable energy consumption-economic growth nexus in emerging countries: a bootstrap panel causality test. Renew Sustain Energy Rev 104:30-37. https://doi.org/10.1016/j. rser.2019.01.020

24. Destek MA, Aslan A (2017) Renewable and non-renewable energy consumption and economic growth in emerging economies: evidence from bootstrap panel causality. Renew Energy 111:757-763. https:// doi.org/10.1016/j.renene.2017.05.008

25. Narayan S, Doytch N (2017) An investigation of renewable and non-renewable energy consumption and economic growth nexus using industrial and residential energy consumption. Energy Econ 68:160-176. https://doi.org/10.1016/j.eneco.2017.09.005

26. Xie F, Liu C, Chen H et al (2018) Threshold effects of new energy consumption transformation on economic growth. Sustainability. 10(11):4124. https://doi.org/10.3390/su10114124

27. Destek MA, Sinha A (2020) Renewable, non-renewable energy consumption, economic growth, trade openness and ecological footprint: evidence from organisation for economic cco-operation and development countries. J Clean Prod 242:118537. https://doi.org/10.1016/j. jclepro.2019.118537

28. Arthur WB (1994) Increasing returns and path dependence in the economy. University of Michigan Press, Ann Arbor

29. Batlle CA (2011) Method for allocating renewable energy source subsidies among final energy consumers. Energy Policy 39:2586-2595

30. Luenberger DG (1995) Microeconomic theory. McGraw-Hill College, New York

31. Chung YH, Färe R, Grosskopf S (1997) Productivity and undesirable outputs: a directional distance function approach. J Environ Manag 51(3):229-240. https://doi.org/10.1006/jema.1997.0146

32. Yörük BK, Zaim O (2005) Productivity growth in OECD countries: a comparison with Malmquist indices. J Comp Econ 33(2):401-420. https:// doi.org/10.1016/j.jce.2005.03.011

33. Kumar S (2006) Environmentally sensitive productivity growth: a global analysis using Malmquist-Luenberger index. Ecol Econ 56(2):280-293. https://doi.org/10.1016/j.ecolecon.2005.02.004

34. Feng G, Serletis A (2014) Undesirable outputs and a primal Divisia productivity index based on the directional output distance function. J Econom 183(1):135-146. https://doi.org/10.1016/j.jeconom.2014.06.014

35. Oh D (2010) A global Malmquist-Luenberger productivity index. J Prod Anal 34(3):183-197 
36. Liddle B (2013) Impact of population, age structure, and urbanization on carbon emissions energy consumption: evidence from macro. Popu Environ 35(3):286-304

37. Ohlan R (2015) The impact of population density, energy consumption, economic growth and trade openness on $\mathrm{CO}_{2}$ emissions in India. Nat Hazards 79(2):1409-1428

38. Becker B, Ivashina V (2014) Cyclicality of Credit Supply: firm Level Evidence. J Monet Econ 62(3):76-93

39. Kim DH, Lin SC et al (2016) Financial structure, firm size and industry growth. Int Rev Econ Financ 41(1):23-39

40. Ebersberger B, Pyka A (2000) Innovation and sectoral employment: a trade-off between compensation mechanisms. Discuss Pap Ser 16(4):635-665

41. Mohseni M, Jouzaryan $F$ (2016) Examining the effects of inflation and unemployment on economic growth in Iran (1996-2012). Procedia Econ Financ 36:381-389

42. Hansen BE (1999) Threshold effects in non-dynamic panels: estimation, testing, and inference. J Econom 93(2):345-368. https://doi.org/10.1016/ S0304-4076(99)00025-1
43. Van der Zwaan B, Rabl A (2004) The learning potential of photovoltaics: implications for energy policy. Energy Policy. 32(13):1545-1554. https:// doi.org/10.1016/S0301-4215(03)00126-5

44. Kobos PH, Erickson JD, Drennen TE (2006) Technological learning and renewable energy costs: implications for US renewable energy policy. Energy Policy 34(13):1645-1658. https://doi.org/10.1016/j.enpol .2004 .12 .008

45. Klitkou A, Bolwig S, Hansen T et al (2015) The role of lock-in mechanisms in transition processes: the case of energy for road transport. Environ Innov Soc Transit 16:22-37. https://doi.org/10.1016/j.eist.2015.07.005

46. Sawhney A, Kahn ME (2012) Understanding cross-national trends in hightech renewable power equipment exports to the United States. Energy Policy. 46:308-318. https://doi.org/10.1016/j.enpol.2012.03.066

\section{Publisher's Note}

Springer Nature remains neutral with regard to jurisdictional claims in published maps and institutional affiliations.

\section{Submit your manuscript to a SpringerOpen ${ }^{\circ}$ journal and benefit from:}

- Convenient online submission

- Rigorous peer review

- Open access: articles freely available online

- High visibility within the field

- Retaining the copyright to your article

Submit your next manuscript at $\gg$ springeropen.com 